Provided for non-commercial research and educational use only. Not for reproduction or distribution or commercial use.

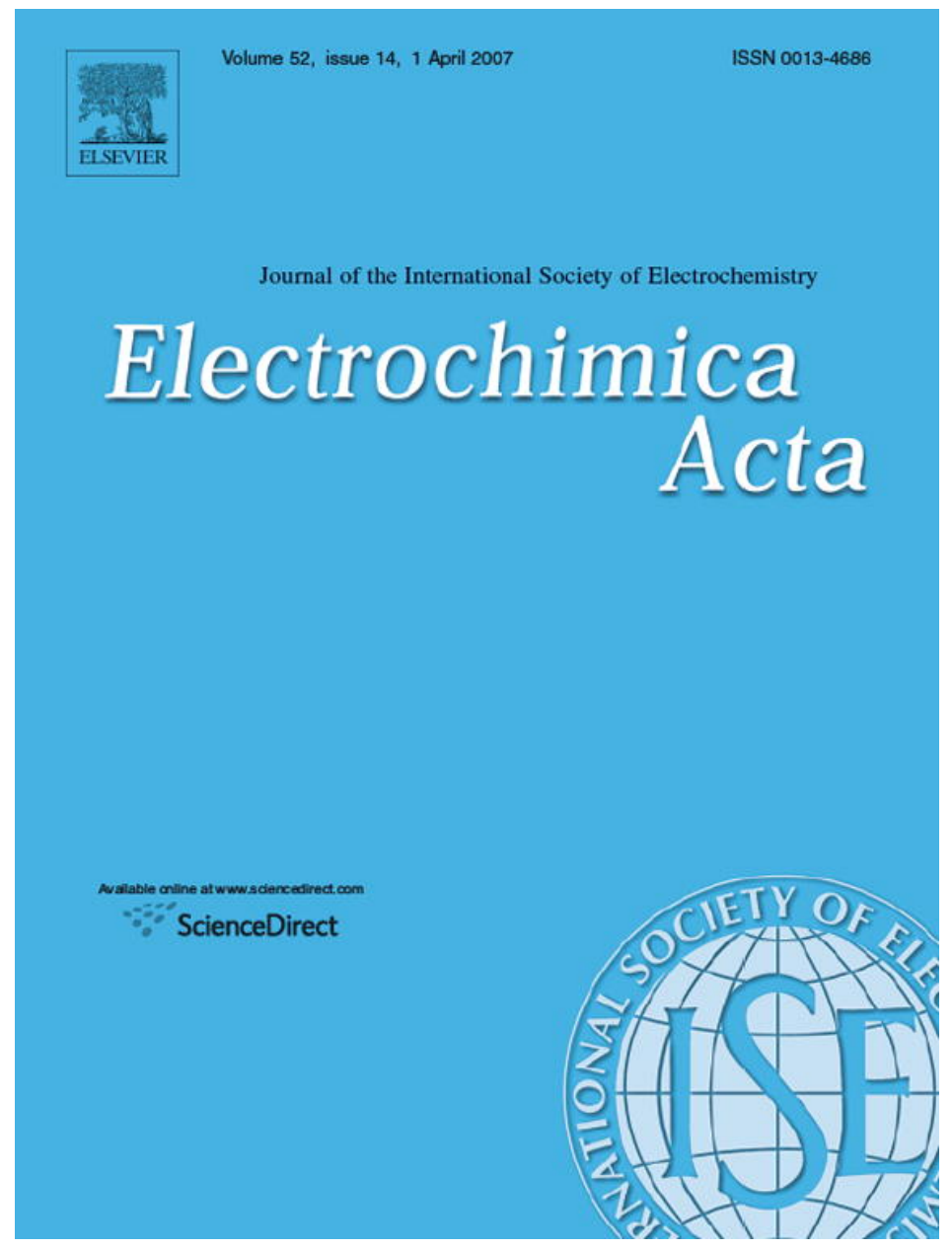

This article was originally published in a journal published by Elsevier, and the attached copy is provided by Elsevier for the author's benefit and for the benefit of the author's institution, for non-commercial research and educational use including without limitation use in instruction at your institution, sending it to specific colleagues that you know, and providing a copy to your institution's administrator.

All other uses, reproduction and distribution, including without limitation commercial reprints, selling or licensing copies or access,

or posting on open internet sites, your personal or institution's website or repository, are prohibited. For exceptions, permission may be sought for such use through Elsevier's permissions site at: 


\title{
Study of structural and electrochemical characteristics of Co-based hypo-hyper d-electrocatalysts for hydrogen evolution
}

\author{
P. Paunović ${ }^{\mathrm{a}, *}$, O. Popovski ${ }^{\mathrm{b}}$, A. Dimitrov ${ }^{\mathrm{a}}$, D. Slavkov ${ }^{\mathrm{a}}$, \\ E. Lefterova ${ }^{c}, S$. Hadži Jordanov ${ }^{a}$ \\ a Faculty of Technology and Metallurgy, University "Sts. Cyril and Methodius" Skopje Rudjer Boskovic 16, 1000 Skopje, Macedonia \\ b Military Academy "Gen. Mihailo Apostolski”, Skopje, Macedonia \\ ${ }^{\mathrm{c}}$ Institute of Electrochemistry and Energy Systems, Bulgarian Academy of Science, Sofia, Bulgaria \\ Received 25 September 2006; received in revised form 28 December 2006; accepted 9 January 2007 \\ Available online 2 February 2007
}

\begin{abstract}
Structural and electrochemical characteristics of hypo-hyper d-electrocatalytic materials aimed for preparation of electrodes for hydrogen evolution were studied. The basic catalytic material was prepared of $10 \%$ amorphous Co (grain size $<2 \mathrm{~nm}$ ), $18 \%$ amorphous $\mathrm{TiO}_{2}$ and $\mathrm{Vulcan}$ $\mathrm{XC}-72$, by sol-gel procedure. A number of modifications were applied aimed at improving the materials performances: (i) $\mathrm{TiO}_{2}$ was transformed into anatase by heating at $480^{\circ} \mathrm{C}$ for $1 \mathrm{~h}$, (ii) multiwalled carbon nanotubes (MWCNT) were used as a catalyst support instead of Vulcan XC-72 and (iii) Mo was added to Co phase in a quantity of 25 at.\% (Mo:Co $=1: 3)$.

Both, material's intrinsic catalytic activity and surface area were affected by these modifications. As a result, the electrocatalytic activity for hydrogen evolution was improved, e.g. transformation of $\mathrm{TiO}_{2}$ into anatase form lowers the HER overpotential $(\eta)$ for $15 \mathrm{mV}$ at $60 \mathrm{mAcm}$. Introduction of MWCNTs lowered $\eta$ for $30 \mathrm{mV}$, while addition of Mo to metallic phase for $40 \mathrm{mV}$.

The complete modification of all three catalyst's components $\left(10 \% \mathrm{MoCo}_{3}+18 \%\right.$ anatase $\left.+\mathrm{MWCNTs}\right)$ was the most effective with $60 \mathrm{mV}$ decrease of overpotential.

Characterization was made by XRD, SEM, IR and XPS methods. Surface area was measured by means of cyclic voltammetry. (C) 2007 Elsevier Ltd. All rights reserved.
\end{abstract}

Keywords: Hydrogen evolution; Hypo-hyper d-electrocatalysis; Co-based electrocatalysts

\section{Introduction}

Platinum is still leading catalytic material for both hydrogen electrolysers and fuel cells. But, there are several barriers that limit its commercial application, as e.g. low abundance and high cost. According to the analysis of Lee et al. [1], present resources are estimated to cover only $\sim 20 \%$ of the automotive industry needs. Pt contributes with more than $50 \%$ in the price of fuel cell stack, just increasing considerably its price. So, actions are taken to reduce or even to replace Pt from fuel cells/hydrogen electrolysers. There are two approaches to solve this problem: (i) increase of real surface area by lowering grain size of the catalytic phase to nano-scale, as well as reducing catalyst loading

\footnotetext{
* Corresponding author. Tel.: +389 23034 392; fax: +389 23034392

E-mail address: pericap@tmf.ukim.edu.mk (P. Paunović).
}

on the electrodes (physical approach) and (ii) development of multicomponent catalysts with catalytic activity comparable or even higher than that of $\mathrm{Pt}$ (chemical approach).

The essence of the chemical approach is to reduce $\mathrm{Pt}$ quantity into catalytic phase by alloying with other elements, e.g. Fe, Ti, Mn, etc., [2,3] or by complete avoiding, e.g. with $\mathrm{Ti}_{1-x} \mathrm{Ni}_{x}, \mathrm{Zr}-\mathrm{Ni}, \mathrm{Ni}-\mathrm{Co}-\mathrm{Mo}, \mathrm{Ni}-\mathrm{W}-\mathrm{S}, \mathrm{Ni}-\mathrm{W}-\mathrm{P}$, etc., [4-7]. The basic aspects of combining d-metals and prediction of structural and electrocatalytic characteristics of the compsite catalysts were given by Jakšić's interpretation [8-10] of Brewer's theory of bonding in transition metals and intermetallic phases [11]. So, significant synergetic effect can be achieved by combining transition metals with dissimilar electronic character, i.e. hyper $\mathrm{d}$-metals having proper individual catalytic activity $(\mathrm{Pt}, \mathrm{Pd}, \mathrm{Ni}$, Co, etc.) with hypo d-metals which are poor individual catalysts (Ti, W, Zr, etc.). Hyper and hypo d-components can be in elemental or valence state as oxides, sulphides or phosphides. 
Classification of the multicomponent catalysts was suggested by present authors elsewhere [12].

The hypo d-electronic phase in hyper d-metallic part is in form of a central atom of either trigonal or tetragonal structure unit. Metallic atoms occupy the outer position in the hypo-hyper structural units, thus being the active places where the HER occurs. The main catalytic activity originates by the hyper dmetallic phase, which prevails on the catalyst's surface, while hypo d-phase contributes to the catalyst's overall synergetic effect by so called strong metal-support interaction (SMSI). The SMSI gives rise to both the electrocatalytic activity of the hyper d-electronic phase (by reinforcing it) and to the catalyst's stability (due to stronger adherence between catalyst's components). SMSI as a basic idea in contemporary catalysis has been termed by Tauster to account for the changes in catalytic activity when metals of VIII group are supported on $\mathrm{TiO}_{2}$ in heterogeneous catalysis [13]. Nanostructured catalysts require much stronger bonding supports, for both long-term stability and higher activity. In this respect titania has an unique role [14].

Recently, carbon nanotubes (CNTs) were used in order to reduce $\mathrm{Pt}$ loading through increasing the catalyst utilization or to improve the activity of the non-platinum catalysts. Compared to traditional carbon blacks, CNTs have many advantages $[1,15,16]$, e.g. $10^{3}-10^{4}$ times higher electric conductivity.

The subject of interest in our research was preparation and characterization of nano-sized non-platinum hypo-hyper d-electrocatalysts that contain $\mathrm{TiO}_{2}$ as hypo d-phase. In our previous work [12] Ni-based catalysts were studied in order to determine the effect of modifications. It was found out that addition of Co into Ni metallic phase had the highest contribution to the rise of catalytic activity. In this work, we are concerned with Co-based catalysts. Modifications like (i) addition of Mo or Ni, (ii) transformation of amorphous $\mathrm{TiO}_{2}$ into crystalline anatase and (iii) replacing Vulcan XC-72 with CNTs were applied first separately, and then together.

\section{Experimental}

The studied catalysts contain $10 \%$ hyper d-metallic phase, $18 \% \mathrm{TiO}_{2}$ as hypo d-component and the rest, carbon substrate. Following organometallics were used as precursors for metallic phase: Me-2,4-pentaedionate (Alfa Aesar, Johnson Matthey, $\mathrm{GmbH}, \mathrm{Me}=\mathrm{Co}$ or $\mathrm{Ni}$ ), $\mathrm{MoO}_{2}$-acetylacetonate (Acros Organics, New Jersey). $\mathrm{TiO}_{2}$ was produced from Ti-isopropoxide (Aldrich, 97\%). As a carbon substrate Vulcan XC-72 (Cabot Corp. Boston, MA) or multiwalled carbon nanotubes (MWCNTs, Guangzhou Yorkpoint Energy Company, China) were used. The catalysts were produced by sol-gel procedure simplified in some steps by the present authors [17]. Basic catalyst contains $\mathrm{Co}, \mathrm{TiO}_{2}$ (thermally treated at $250^{\circ} \mathrm{C}$ ) and Vulcan $\mathrm{XC}-72$ in amount as given above.

To indicate synergetic effect of this type of hypo-hyper dcatalyst, corresponding Co catalyst deposited only on Vulcan $\mathrm{XC}-72$ was prepared.

The basic catalyst was further modified for improving its catalytic activity. All components were modified separately: (i) $\mathrm{TiO}_{2}$ was thermally treated at $480{ }^{\circ} \mathrm{C}$, (ii) multiwalled carbon
Table 1

Composition of the studied electrocatalysts

\begin{tabular}{llll}
\hline Sample no. & $\begin{array}{l}\text { Hypo-oxide } \\
\text { d-phase }(18 \%)\end{array}$ & $\begin{array}{l}\text { Carbon substrate } \\
(72 \%)\end{array}$ & $\begin{array}{l}\text { Hyper-metal } \\
\text { d-phase }(10 \%)\end{array}$ \\
\hline 1 & - & Vulcan XC-72* & $\mathrm{Co}$ \\
$2^{* *}$ & $\mathrm{TiO}_{2}\left(250^{\circ} \mathrm{C}\right)$ & Vulcan XC-72 & $\mathrm{Co}$ \\
3 & $\mathrm{TiO}_{2}\left(480^{\circ} \mathrm{C}\right)$ & Vulcan XC-72 & $\mathrm{Co}$ \\
4 & $\mathrm{TiO}_{2}\left(250^{\circ} \mathrm{C}\right)$ & MWCNTs & $\mathrm{Co}$ \\
5 & $\mathrm{TiO}_{2}\left(250^{\circ} \mathrm{C}\right)$ & Vulcan XC-72 & $\mathrm{MoCo}_{3}^{* * *}$ \\
6 & $\mathrm{TiO}_{2}\left(480^{\circ} \mathrm{C}\right)$ & MWCNTs & $\mathrm{MoCo}_{3}$
\end{tabular}

\footnotetext{
* In this sample there is no $\mathrm{TiO}_{2}$, so the content of Vulcan XC-72 is $90 \%$.

** Sample no. 2 is the basic catalyst, the subject of further modifications.

*** In this case $\mathrm{MoCO}_{3}$ does not means existence of intermetallic phase, but just denotes atomic ratio of $\mathrm{Mo}: \mathrm{Co}=1: 3$
}

nanotubes were used instead of Vulcan XC-72 and (iii) Mo was added into hyper d-metallic phase. Further, the basic catalyst was modified on the whole. The composition of the investigated electrocatalysts is shown in Table 1.

To identify the intrinsic changes caused by the modifications, spectroscopic and structural techniques were employed. So, XRD and SEM techniques were used for structural characterization. XRD measurements were carried out by X-Ray diffractometer Philips APD 15, with $\mathrm{Cu} \mathrm{K} \alpha$ radiation, while SEM observations were performed by Scanning Electron Microscope JEOL, model JEM 200 CX. A presence of surface valence-state phases of the catalyst's components was determined by XPS spectroscopy, ESCALAB MK II, VG Scientific, England, using $\mathrm{Al} \mathrm{K} \alpha$ radiation. Infrared spectroscopy was employed to determine the strength of hypo-hyper d-interaction $\left(\mathrm{TiO}_{2} / \mathrm{Co}\right)$, using FTIR spectrometer, model Bruker Vector 22.

Catalysts surface area was determined trough double layer capacity, measured by cyclic voltammetry $[18,19]$. The ratio of real versus geometric surface area of the electrodes can be determined as a quotient of catalyst's double layer capacity $C_{\mathrm{dl}}$ versus double layer capacity $C_{\mathrm{dlo}}$ of pure oxide surface.

Further, the produced catalysts were electrochemically tested for hydrogen evolution reaction. Porous electrodes aimed for three phase operation (solid electrode, liquid electrolyte and $\mathrm{H}_{2}$ gas as a product) were prepared. They consist of two layers: (i) catalytic layer facing the electrolyte, covered by catalyst with low amount of PTFE and (ii) gas-diffusion layer facing the gas side consisted of Vulcan XC-72 (or MWCNTs) bonded with PTFE. The procedure of electrode preparation is described elsewhere [20]. Electrochemical investigations were performed using AMEL equipment (Function Generator AMEL 568, Potentiostate/Galvanostate 2053 and software package SOFTASSIST 2.0). The counter electrode was of platinum wire and the reference electrode- $\mathrm{Hg} / \mathrm{HgO}$. The electrolyte was an aqueous solution of 3.5 M KOH (p.a., Merck) at room temperature.

\section{Results}

\subsection{Polarization characteristics}

Shown in Fig. 1 are the polarization curves in both $i-\eta$ and $\log i-\eta$ plots for hydrogen evolution reaction (HER) for the 

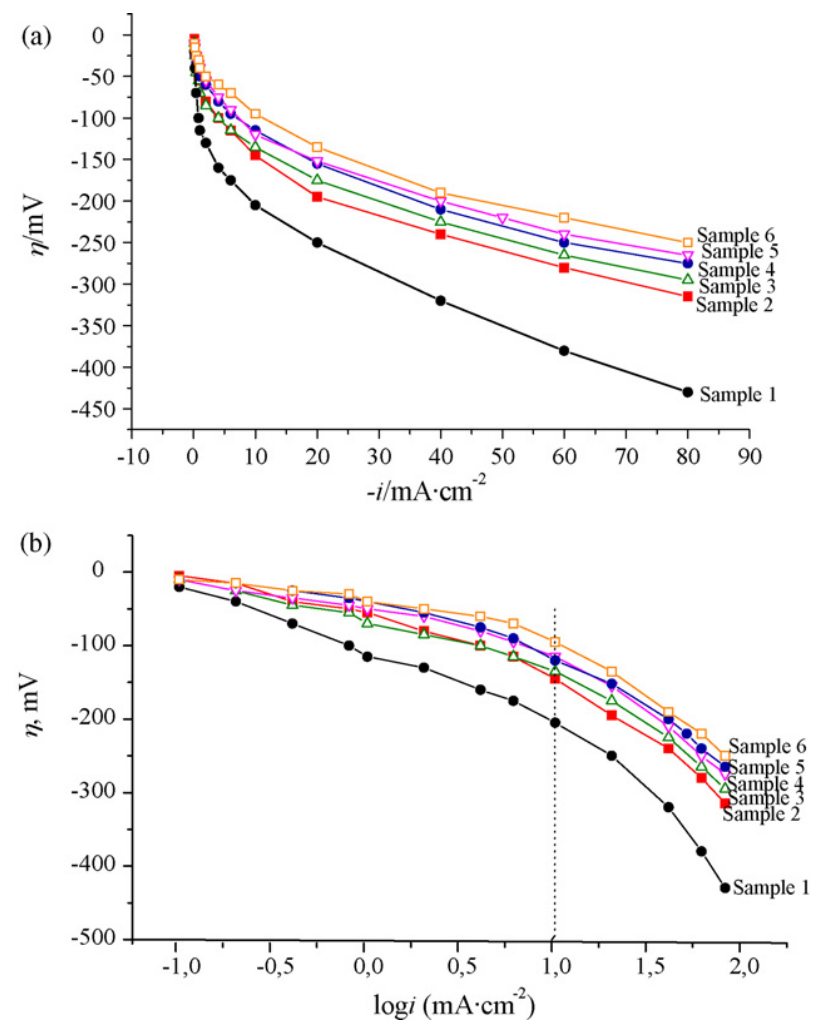

Fig. 1. Polarization curves of investigated hypo-hyper d-electrocatalysts in the plot (a) $i-\eta$ and (b) $\log i-\eta$.

studied electrocatalysts scanned by steady-state galvanostatic method.

Comparing curves of samples 1 and 2 the synergetic influence of $\mathrm{TiO}_{2}$ addition could be observed. Namely, the basic hypo-hyper d-electrocatalyst (sample 2) shows $100 \mathrm{mV}$ decrease of HER overpotential at $60 \mathrm{~mA} \mathrm{~cm}^{-2}$ (accepted as reference c.d.), as compared to pure Co catalyst (sample 1, see Table 2). Other separate modifications of the components, cause as well rise of catalytic activity (see Fig. 1 and Table 2). This improvement of catalytic activity can be observed by the corresponding values of Tafel slopes shown in Table 2.

Normally, the most pronounced improvement of electrode activity was observed when all three catalyst components were modified. HER overpotential is now lower for $60 \mathrm{mV}$ compared to the basic catalyst or even for $160 \mathrm{mV}$ compared to the catalyst that contains only Co (sample 1 ).

Table 2

Overpotentials at $60 \mathrm{~mA} \mathrm{~cm}^{-2}$ for hydrogen evolution reaction of the studied electrocatalysts and overpotential difference related to the basic catalyst

\begin{tabular}{lccl}
\hline $\begin{array}{l}\text { Sample no. } \\
\text { (see Table 2) }\end{array}$ & $\eta_{60}(\mathrm{mV})$ & $\begin{array}{l}\Delta \eta_{60}, \mathrm{mV}(\mathrm{vs} . \\
\text { basic catalyst })\end{array}$ & $\begin{array}{l}\text { Tafel slope } b \\
(\mathrm{mV} \mathrm{decade}\end{array}$ \\
\hline 1 & -380 & -100 & 90 \\
2 & -280 & 0 & 70 \\
3 & -265 & 15 & 60 \\
4 & -250 & 30 & 50 \\
5 & -240 & 40 & 50 \\
6 & -220 & 60 & 40 \\
\hline
\end{tabular}
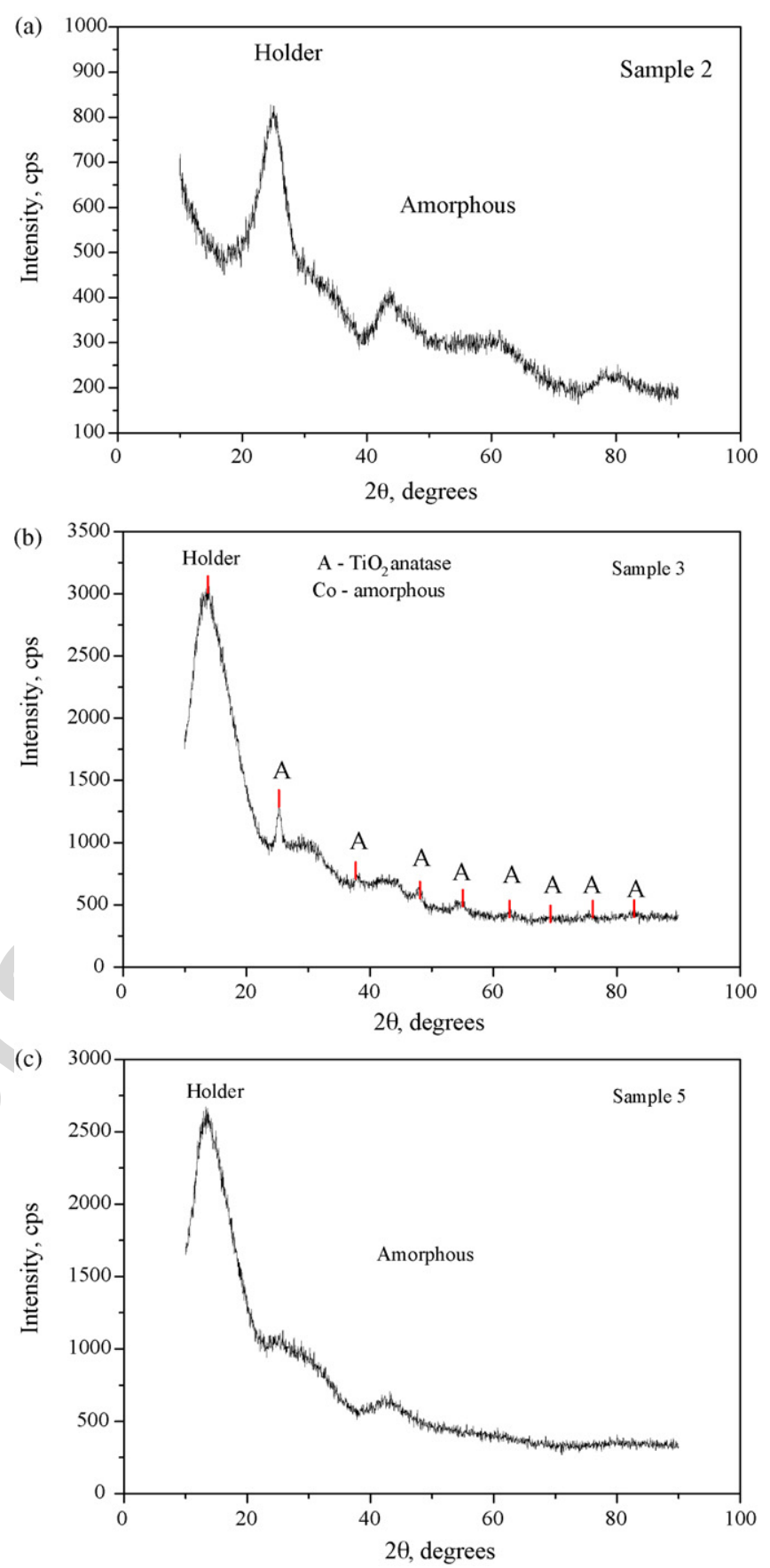

Fig. 2. XRD spectra of catalysts containing (a) $10 \% \quad \mathrm{Co}+18 \% \quad \mathrm{TiO}_{2}$ $\left(250{ }^{\circ} \mathrm{C}\right)+$ Vulcan XC-72 (sample 2), (b) $10 \% \mathrm{Co}+18 \% \mathrm{TiO}_{2}\left(480{ }^{\circ} \mathrm{C}\right)+$ Vulcan $\mathrm{XC}-72$ (sample 3 ) and (c) $10 \% \mathrm{MoCo}_{3}+18 \% \mathrm{TiO}_{2}\left(250^{\circ} \mathrm{C}\right)+$ Vulcan $\mathrm{XC}-72$ (sample 5).

Changes of polarization characteristics are caused by the applied modifications, as confirmed by the comprehensive characterization of catalyst's structure and surface.

\subsection{XRD analysis}

XRD patterns of some catalysts are shown in Fig. 2. As can be seen, in all cases Co as hyper d-metallic phase is amorphous, with grain size lower than $2 \mathrm{~nm}$. $\mathrm{TiO}_{2}$ as hypo d-oxide phase 
(a)

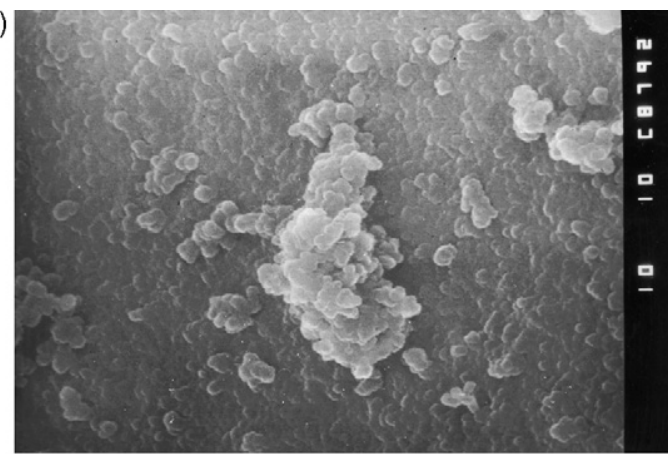

(c)

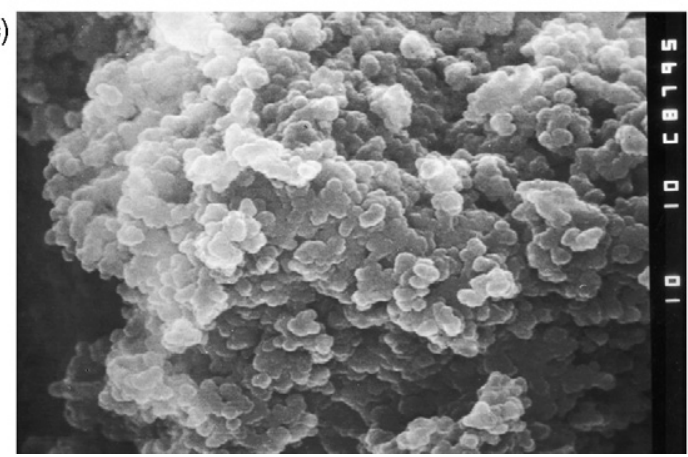

(b)

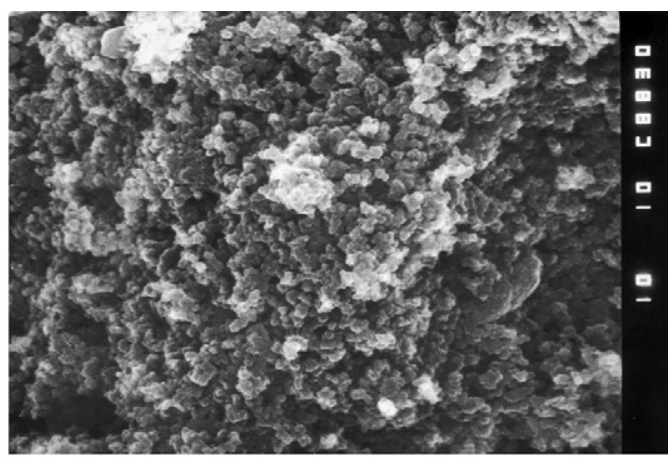

(d)

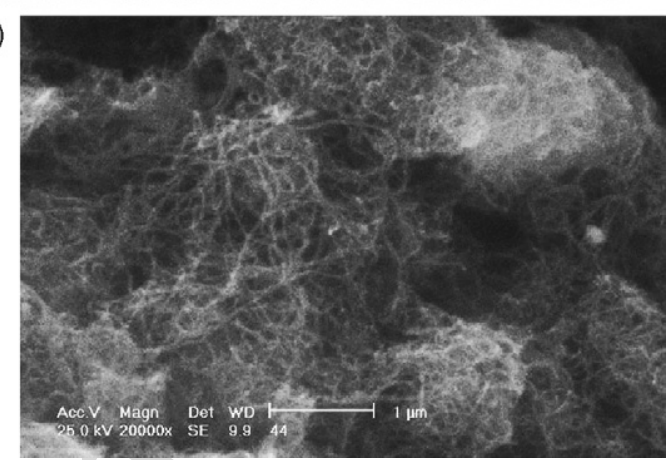

Fig. 3. SEM photographies of: catalyst's support $\left(\mathrm{TiO}_{2}\left(250^{\circ} \mathrm{C}\right)\right.$ on Vulcan XC-72), $\times 10000$; (b) pure Co deposited on Vulcan XC-72 (sample 1), $\times 10000 ;(\mathrm{c})$ basic hypo-hyper d-electrocatalyst (sample 2), ×10000; (d) catalyst with modified carbon substrate (sample 4), $\times 20000$.

treated at $250^{\circ} \mathrm{C}$ (Fig. 2a and c) was not detected by XRD, thus suggesting its amorphous nature. By increasing the temperature of thermal treatment up to $480^{\circ} \mathrm{C}$ (Fig. 2b) the amorphous $\mathrm{TiO}_{2}$ phase is transformed into crystalline one (anatase) with grain size of 7-8 nm. In the mixed metallic system Mo-Co there is no characteristic peak for Mo metallic phase, meaning that Mo is amorphous too.

\subsection{SEM analysis}

Shown in Fig. 3 are SEM microphotographies of some characteristic catalysts. Generally, the morphology of these catalysts is very similar to that of Ni-based catalysts studied in the previous work [12]. The catalyst's particles deposited on Vulcan are of a spherical shape (Fig. 3a-c). There is a grouping of the particles in clusters, whereat good adherence between particles is achieved. In Fig. 3a the catalyst support, i.e. $\mathrm{TiO}_{2}$ deposited on Vulcan XC-72 is shown. There is good uniformity of particles size and shape. The size of clusters is roughly $50-100 \mathrm{~nm}$. In the case of Co deposited on Vulcan XC-72 (sample 1, Fig. 3b) the clusters are bigger, 100-120 nm (Fig. 2b). Further, by deposing Co on Vulcan XC-72 $+\mathrm{TiO}_{2}$ the basic catalyst (sample 2) is formed as a whole, with larger clusters that reach 150-200 nm (Fig. 3c). The particles are not uniformly distributed, and a number of holes appear between the aggregates. This contributes to the higher specific surface area, and consequently to a higher electrocatalytic activity.

Catalyst deposited on MWCNTs shows completely different morphology (Fig. 2d). The particles of oxide and metallic phases grafted on MWCNTs are grouped in smaller clusters than those on Vulcan XC-72. Due to intrinsic geometric shape of MWCNTs (empty cylinders with well developed surface area), they possess inner holes. So the inner porosity of MWCNTs is considerably higher. This contributes to better dispersion of the active catalytic centers over the surface, and causes higher catalytic activity.

SEM analysis is not sufficient to give information on the nature of bonding (mechanical or chemical) of hypo and hyper d-components into the catalyst's clusters. In order to obtain this information further spectroscopic investigation was performed by means of infrared spectroscopy and X-ray photoelectron spectroscopy (XPS).

\subsection{Infrared analysis}

The only band of interest on the catalysts FTIR spectra originates by $\mathrm{TiO}_{2}$ [21] (Fig. 4). These bands are compared with corresponding ones originated from pure $\mathrm{TiO}_{2}$ produced in the same conditions as the catalysts. The peaks of the bands of $\mathrm{TiO}_{2}$ from the catalysts are shifted to higher value of wave number compared with the corresponding peak of pure $\mathrm{TiO}_{2}$. This means that interaction between hypo d-oxide and hyper d-metallic phase exists, i.e. strong metal-support interaction (SMSI) is detected. The higher the shift of wave number, the shorter the bonds between $\mathrm{TiO}_{2}$ and hyper d-metallic phase, i.e. the stronger the hypo-hyper d-interaction. The existence of hypo-hyper d-interaction causes changes in adsorption characteristics of the electrode materials and synergetic electrocatalytic effect for hydrogen evolution reaction [9].

The peak difference between basic catalyst and pure $\mathrm{TiO}_{2}$ is $55 \mathrm{~cm}^{-1}$ (Fig. 4a). Corresponding shift of wave number for 

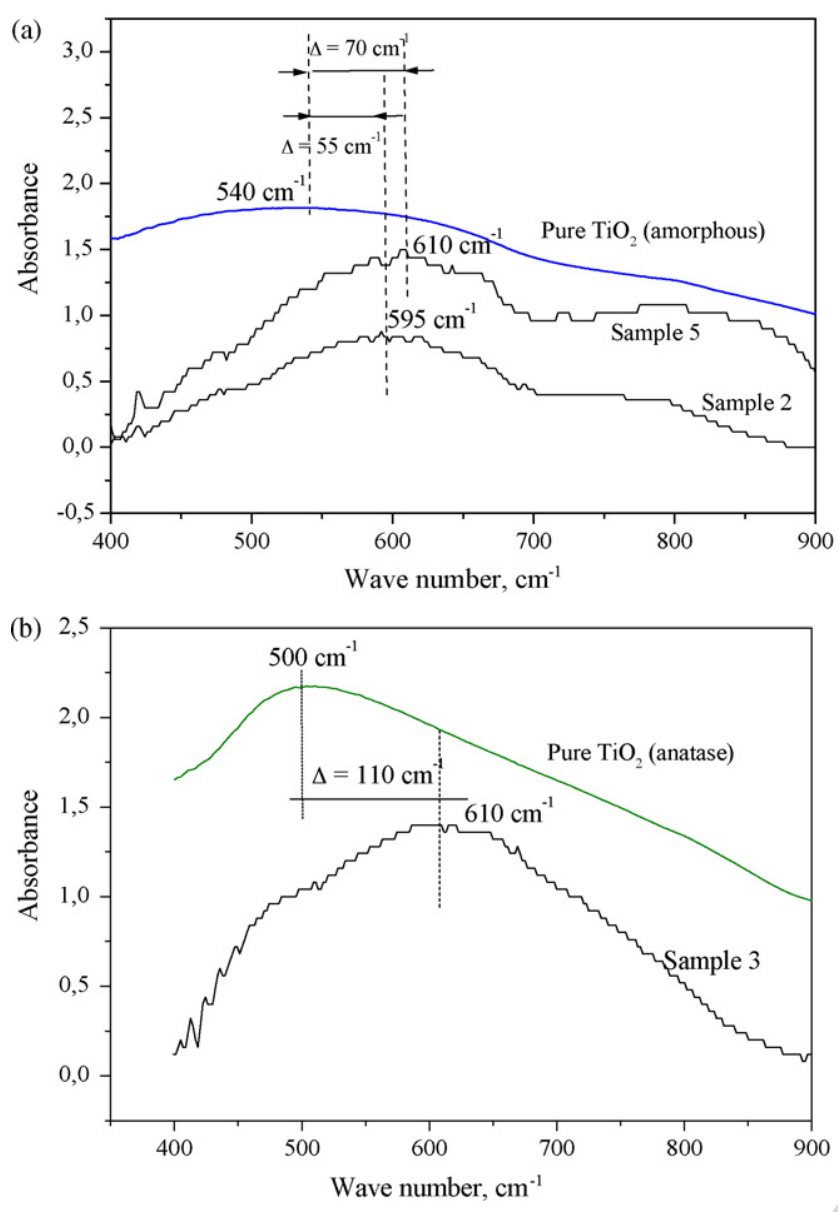

Fig. 4. Infrared spectra of $\mathrm{TiO}_{2}$ originated from pure $\mathrm{TiO}_{2}$ thermally treated at: (a) $250{ }^{\circ} \mathrm{C}$ and (b) $480{ }^{\circ} \mathrm{C}$ and from corresponding catalysts.

the catalyst containing Mo into metallic phase (sample 5) is $70 \mathrm{~cm}^{-1}$. The stronger SMSI in this case is a result of a double hypo-hyper d-interaction $\left(\mathrm{Co}-\mathrm{TiO}_{2}\right.$ and $\left.\mathrm{Co}-\mathrm{Mo}\right)$. The shift of peak of $\mathrm{TiO}_{2}$ in the sample $3\left(\mathrm{TiO}_{2}\right.$ thermally treated at $\left.480{ }^{\circ} \mathrm{C}\right)$ is $110 \mathrm{~cm}^{-1}$ related to the peak of pure $\mathrm{TiO}_{2}$ (anatase) (Fig. 4a). So, hypo-hyper d-interaction $\mathrm{Co}-\mathrm{TiO}_{2}$ (anatase) is twice stronger than in case of amorphous $\mathrm{TiO}_{2}$. Thus, it is normal to expect that the adsorption and catalytic characteristics of these catalysts to be higher related to the basic hypo-hyper d-electrocatalyst (sample 2).

Shown in Table 3 are the shifts of $\mathrm{TiO}_{2}$ peaks for all catalysts. On can say that (a) intensity of hypo-hyper d-interaction

Table 3

Differences of maximum values of wave number of $\mathrm{TiO}_{2}$ bands originated by electrocatalysts vs. corresponding ones of pure $\mathrm{TiO}_{2}$

\begin{tabular}{lc}
\hline Sample no. & $\Delta$ wave number $\left(\mathrm{cm}^{-1}\right)$ \\
\hline 1 & - \\
2 & 55 \\
3 & 110 \\
4 & 55 \\
5 & 70 \\
6 & 130 \\
\hline
\end{tabular}

depends on the thermal treatment of $\mathrm{TiO}_{2}$ and (b) the shifts are the same for catalysts with identical $\mathrm{TiO}_{2}$ treatment.

\subsection{XPS analysis}

XPS investigation was performed to identify the valence state of the catalyst's components on the surface. In Fig. 5a the spectra originated by $\mathrm{TiO}_{2}$ are shown. The values of characteristic binding energy peaks of Ti2 $\mathrm{p}_{1 / 2}$ and $\mathrm{Ti} 2 \mathrm{p}_{3 / 2}$ are 464.7 and $458.9 \mathrm{eV}$, respectively. The first one is identical to the tabulated value which correspond to $\mathrm{TiO}_{2}$ [22], while the second one is higher for $0.3 \mathrm{eV}$ than the tabulated value $(459.2 \mathrm{eV})$. This shift of the theoretic value suggests some interaction of $\mathrm{TiO}_{2}$ with the metallic phase. This suggestion is supported by the fact that the peaks are non-symetric and stretched. The difference between standard binding energy of Ti2 $\mathrm{p}_{1 / 2}$ and $\mathrm{Ti} 2 \mathrm{p}_{3 / 2}$ is $5.7 \mathrm{eV}$ what corresponds to existence of $\mathrm{TiO}_{2}$ phase.

The positions of the corresponding peaks of $\mathrm{Co} 2 \mathrm{p}_{1 / 2}$ and $\mathrm{Co} 2 \mathrm{p}_{3 / 2}(797.6$ and $782.0 \mathrm{eV})$ as well as corresponding satellite peaks (787.5 and $803.5 \mathrm{eV}$, see Fig. 5b) imply existence of $\mathrm{Co}^{2+}$ as $\mathrm{Co}(\mathrm{OH})_{2}$ on the catalyst's surface. But, considering the binding energy range on the peak's basis, one can consider that a part of $\mathrm{Co}^{2+}$ exists as $\mathrm{CoO}$, i.e. $\mathrm{CoTiO}_{3}$. So, the satellite peaks are result of the paramagnetism of the $\mathrm{CoO}[23,24]$. The presence of $\mathrm{CoTiO}_{3}$ confirms the hypo-hyper d-interaction detected by IR analysis.

The values of binding energy maxima related to $\mathrm{Mo} 3 \mathrm{~d}_{3 / 2}$ and Mo3d $\mathrm{d}_{5 / 2}$ indicate existence of $\mathrm{Mo}^{3+}$ as $\mathrm{Mo}_{2} \mathrm{O}_{3}$ at the catalyst's surface.

\subsection{Real versus geometrical surface area}

In order to clarify whether the achieved catalyst activity is caused by the purely mechanical factor (increased surface area) or by rise of intrinsic catalytic activity, surface area of both supporting materials, MWCNTs and Vulcan XC-72, were determined.

Measuring of capacity of double layer $\left(C_{\mathrm{dl}}\right)$ in potential region where charging/discharging of the double layer ( $\mathrm{dl})$ is the only process, was adopted as the most convenient method for "in situ" determination of the real surface area. Current density of dl charging, $i_{\text {cap }}$, at the middle of potential scanning interval was averaged. It changes linearly with the scanning rate $\left(v=1-10 \mathrm{mV} \mathrm{s}^{-1}\right)$, the plot $i_{\text {cap }}-v$ being equal to the $C_{\mathrm{dl}}$ of the electrode surface. Knowing the $C_{\mathrm{dl}}$ per unit area one can easily determine the value of the real surface area. This procedure was practically the only possible for our study, due to a number of limitations for use of alternative and possibly more accurate techniques for surface area determination.

$C_{\mathrm{dl}}$ values were determined for both support materials, before and after application of the active layer. $C_{\mathrm{dl}}$ at pure MWCNTs was $331 \mathrm{mF} \mathrm{cm}^{-2}$ and at Vulcan XC-72 almost one half of this value, i.e. $179 \mathrm{mF} \mathrm{cm}^{-2}$ [25]. MWCNTs are known as materials with highly developed surface area and this is confirmed by these $C_{\mathrm{dl}}$ values. Some lower values were measured at catalyst materials (support + active layer), i.e. $\sim 310 \mathrm{mF} \mathrm{cm}^{-2}$ for MWCNTs supported catalysts (sample 4 and 6, see Table 4) and 

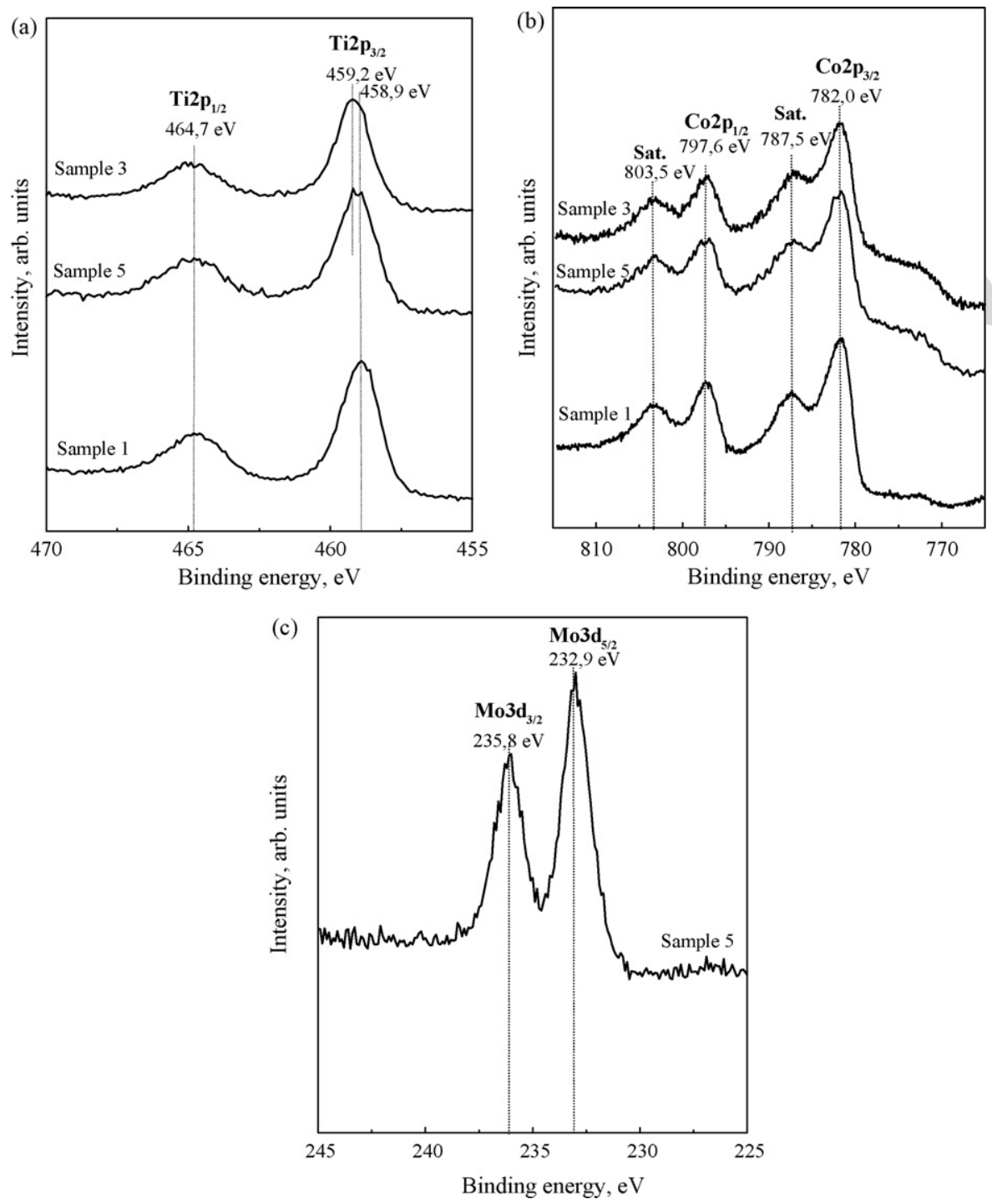

Fig. 5. XPS spectra originated by (a) $\mathrm{Ti}^{4+}$, (b) $\mathrm{Co}^{2+}$ and (c) $\mathrm{Mo}^{3+}$.

155-207 $\mathrm{mF} \mathrm{cm}^{-2}$ for Vulcan XC-72 supported catalysts. Again the ratio of the compared surface areas is near 2:1 in favor of MWCNTs.

The constant ratio of $C_{\mathrm{dl}}$ for both bare and covered support materials is a proof that the measured high activities of MWCNTs supported catalysts are caused by purely physical factor of well developed surface area.

Table 4

Double layer capacity, $C_{\mathrm{dl}}$ of catalysts and pure carbon supports

\begin{tabular}{lll}
\hline Sample no. & Used carbon support & $C_{\mathrm{dl}}\left(\mathrm{mF} \mathrm{cm}^{-2}\right)$ \\
\hline 1 & Vulcan XC-72 & 155 \\
2 & Vulcan XC-72 & 154 \\
3 & Vulcan XC-72 & 207 \\
4 & MWCNTs & 306 \\
5 & Vulcan XC-72 & 204 \\
6 & MWCNTs & 309 \\
Pure MWCNTs & $/$ & 331 \\
Pure Vulcan XC-72 & $/$ & 179 \\
\hline
\end{tabular}

\section{Discussion}

\subsection{Synergetic effect}

A general conclusion of the results for the Ni-based hypo-hyper d-systems presented in our previous work [12] was that addition of Co into hyper d-metallic phase has the highest contribution to the improvement of catalytic activity of the basic Ni-catalyst. That was why we decided to move on investigation of Co-based systems.

Let us start with comparison of the polarization curves of Co catalyst deposited on Vulcan XC-72 (sample 1) and the one with involved hypo d-phase $-\mathrm{TiO}_{2}$ (sample 2). It is obvious that involving $\mathrm{TiO}_{2}$ into the catalyst produces synergetic effect. This is expressed with lowering of overpotential for $100 \mathrm{mV}$ (see Fig. 1a and Table 2) as well as with lower value of Tafel slope (see Table 2). Further structural investigations support this statement. So, IR measurements showed existence of intrinsic hypo-hyper d-interaction, i.e. strong metal-support interaction (SMSI) (see Fig. 4a and Table 3). Also XPS analysis suggests presence of 
some amount of $\mathrm{CoTiO}_{3}$. On the other side, the real surface area is almost the same, according to values of $C_{\mathrm{dl}}$ in Table 4 . Thus, improvement of the catalytic activity for hydrogen evolution is result only of intrinsic interaction between $\mathrm{TiO}_{2}$ and Co metallic phase.

HER overpotential is for $205 \mathrm{mV}$ lower on basic Co-catalyst (sample 2) than on the corresponding Ni-based catalyst $(10 \%$ $\mathrm{Ni}+\mathrm{TiO}_{2}\left(250^{\circ} \mathrm{C}\right)+$ Vulcan $\left.\mathrm{XC}-72\right)$ [12]. This is result of very small size of Co grains (high developed surface area) as active catalytic centers and their high dispersion over the catalyst's surface. Thus, in the Co-based systems, high activity is achieved even with the basic catalyst.

\subsection{Modification of hypo d-oxide phase}

Next was modification of $\mathrm{TiO}_{2}$. Catalyst with crystalline $\mathrm{TiO}_{2}$ was more active than the basic one (with amorphous $\mathrm{TiO}_{2}$ ) and the one of pure Co only. The corresponding HER overpotentials were lower for 15 and $115 \mathrm{mV}$ for pure Co, respectively. Tafel slope was as well lower: $60 \mathrm{mV}$ decade ${ }^{-1}$ for modified $\mathrm{TiO}_{2}$,

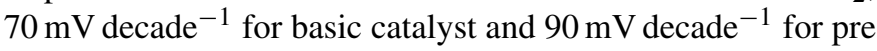
Co only.

The measured rise of activity was attributed to stronger hypo-hyper d-interaction between Co and anatase. SMSI is twice as strong as in the case of amorphous $\mathrm{TiO}_{2}$ (see Fig. $4 \mathrm{~b}$ and Table 3). Almost symbolic rise of activity ( $15 \mathrm{mV}$ lower HER overpotential) despite of twice strong interaction is explained in terms of the size of Co particles. They are so small (lower than $2 \mathrm{~nm}$ ) and uniformly dispersed over the surface so that high activity is achieved even in the stage of basic catalyst and there is no left possibility for significant increase due to the transformation of $\mathrm{TiO}_{2}$ into crystalline shape. Situation is quite different with Ni-based systems where basic catalyst is not so active and there is a possibility for HER overpotential decrease for $60 \mathrm{mV}$ at $60 \mathrm{~mA} \mathrm{~cm}^{-2}$ [12].

\subsection{Modification of carbon substrate}

Involving MWCNTs as carbon substrate causes a decrease of overpotential for $30 \mathrm{mV}$ related to the basic catalyst. This rise of the catalytic activity has different character than with the previous modification. According to the results of IR analysis (Table 3), the hypo-hyper d-interaction in this case is the same as in basic catalyst, so the rise of catalytic activity is result of purely physical factor of well developed surface area of the catalyst. This is evident from the value of $C_{\mathrm{dl}}$ that is almost twice than that of the basic catalyst (see Table 4). Nevertheless, there is no remarkable rise of activity as in the case of Ni-based catalyst (even $120 \mathrm{mV}$ overpotential difference [12]). Namely active catalytic centers (Co particles) already possess very high surface area (grain size lower than $2 \mathrm{~nm}$ ) and are very well dispersed over the surface, so that increase of surface area of the catalyst as a whole does not produce pronounced rise of catalytic activity, as in Ni system, where active catalytic centers are crystals sized 15-20 nm [26].

The improvement of catalytic activity by involving carbon nanotubes is a result of several factors, as e.g.: (i) rise of real surface area of the catalyst as a whole, (ii) better dispersion of catalyst's particles over the surface, (iii) extra-conductive properties and (iv) geometric nature of nanotubes. Extra-conductive properties enable easier electron exchange with hydrogen protons, what intensifies formation of adsorbed hydrogen atoms and further hydrogen molecules. On the other side, MWCNT's high inter- and trans-particle porosity as well as its geometry (empty cylinders), do facilitates the escape of hydrogen molecules from catalyst's surface. Some previous researches have sown that classic carbon blacks as Vulcan XC-72 have large ratio of micropores, which are smaller than $2 \mathrm{~nm}$, while carbon nanotubes have no pores smaller than $2 \mathrm{~nm}$ [15]. This is evidence that MWCNTs have higher available surface area.

\subsection{Modification of hyper d-metallic phase}

Different metals were considered as possible additives to Co metallic phase in order to improve its catalytic activity. $\mathrm{Ni}$ as the most active non-precious hyper d-metal [27] did not perform satisfactorily. The activity of basic Co catalyst (sample 2) is higher than that of corresponding CoNi-based catalyst [12]. Finally, according to Jakšić [9], Mo was chosen to be added into hyper d-metallic phase.

So, addition of molybdenum in the atomic ratio $\mathrm{Mo:Co}=1: 3$ produced an increase of catalytic activity of basic catalysts higher than with the previous two modifications. Overpotential for hydrogen evolution at $60 \mathrm{~mA} \mathrm{~cm}^{-2}$ is for $40 \mathrm{mV}$ lower than that of basic catalyst. The value of Tafel slope was $50 \mathrm{mV}$ decade $^{-1}$ versus corresponding ones of both basic catalyst $\left(70 \mathrm{mV}\right.$ decade $\left.^{-1}\right)$ and pure $\mathrm{Co}\left(90 \mathrm{mV}\right.$ decade $\left.^{-1}\right)$. This points out on increase of intrinsic catalytic activity. The results of IR analysis (Fig. 4b and Table 3 ) and $C_{\mathrm{dl}}$ (Table 4), suggest that this increase is result of both rise of hypo-hyper d-interaction and slight rise of real surface area. But the rise of real surface area (near 30\%) is not so pronounced as with the MWCNTs. So, the prevailing effect in the increase of the catalytic activity has multiplied hypo-hyper d-interaction $\left(\mathrm{Co}-\mathrm{TiO}_{2}\right.$ and $\left.\mathrm{Co}-\mathrm{Mo}\right)$, expressed by higher shift of the IR maximum (Fig. 4a). Namely, the changes of electron structure caused by hypo d-phase and mutual sharing of d-orbitals provides electronic configuration more suitable for $\mathrm{H}^{+}$adherence and transference [9]. The electron density near hyper d-metal is higher in the alloy than in a pure state, due to electron transfer from the surrounding atoms of hypo d-phase [28,29]. In this case, hydrogen evolution near the metal atoms should be favored in the composite catalyst rather than in pure hyper d-metal.

\subsection{Complete modification}

A catalyst was prepared with application of all three modifications, i.e. addition of $\mathrm{Mo}, \mathrm{TiO}_{2}$ as anatase and MWCNTs (sample 6). As expected, it performed the best and HER overpotential was lower for $60 \mathrm{mV}$ related to the basic catalyst (sample 2) or $160 \mathrm{mV}$ related to the only Co-containing catalyst (sample 1). This increase of the activity is a result of both higher hypo-hyper d-interaction and more developed surface area. In this case, shift of the IR band maximum is the highest between 
all catalysts, even $130 \mathrm{~cm}^{-1}$ (Table 3 ), while real surface area is almost twice related to the basic catalyst (Table 4). But the value of $\mathrm{C}_{\mathrm{dl}}$ is almost the same as in the case of only carbon substrate modification, so physical effect of surface area is not so pronounced. Thus, higher contribution in improving of the catalytic activity has the increase of intrinsic hypo-hyper d-interaction. In addition, the value of Tafel slope, $40 \mathrm{mV} \mathrm{decade}^{-1}$ versus $90 \mathrm{mV} \mathrm{decade}^{-1}$ of pure Co (sample 1) or $70 \mathrm{mV} \mathrm{decade}^{-1}$ of basic catalyst (sample 2), proves that there is significant rise of intrinsic catalytic activity.

In the Co-based system the final effect of complete modification is not so pronounced as in case of Ni-based systems [12]. But, if one analyses from the beginning of the previous investigations [12] to the end of these investigations, starting with pure Ni deposited on Vulcan XC-72, ending with composite non-platinum catalyst containing $\mathrm{MoCo}_{3} / \mathrm{TiO}_{2} / \mathrm{MWCNTs}$, one can register remarkable improvement of the catalytic activity, quantitatively expressed with $315 \mathrm{mV}$ decrease of overpotential at c.d. of $60 \mathrm{~mA} \mathrm{~cm}^{-2}$. This was the main goal of our research.

One should mention that three dimensional gas-diffusion electrodes could possibly acquire lower activity at higher current densities (as compared to, e.g. Raney-Ni or Raney-Ni activated electrodes) due to the nature of their structure. If evolved hydrogen could not escape out of the subcritically sized pores, then the effectively operating surface area (of such 3D electrodes) is lower than the real one. Similar phenomenon was found and was discussed by Rausch and Wendt [30]. Possible explanation for this disadvantage is that it is due to lower content of metallic phase $(10 \%)$ as compared to $20 \%$ in other catalysts for HER.

\section{Conclusion}

Investigations are presented aimed to obtain nano-sized Co electrocatalysts for hydrogen evolution. This study completes the previous one with Ni-based catalysts [12].

Performances are compared of three types of catalysts for HER, pure Co catalyst system, basic Co catalyst system and improved catalysts systems.

Basic catalyst system performs much better than the pure Co catalyst system, as expressed by the $100 \mathrm{mv}$ lower overpotential for HER at $60 \mathrm{~mA} \mathrm{~cm}^{-2}$.

Transformation of $\mathrm{TiO}_{2}$ into anatase was the least effective-HER overpotential was lower only $15 \mathrm{mV}$ versus basic Co catalyst system. Use of MWCNTs instead of Vulcan XC-72 was intermediate HER overpotential was lower for $30 \mathrm{mV}$. Modification of the metallic phase in the basic catalyst by use of $\mathrm{MoCo}_{3}$ instead of pure Co was the most effective one. It did lower HER overpotential for $40 \mathrm{mV}$.

Improvement of the catalytic activity is result of both: rising intrinsic hypo-hyper d-interaction as result of introducing anatase and Mo and increase of real surface area caused by involving MWCNTs as carbon substrate. Higher contribution in improvement of catalytic behavior for HER was attributed to the addition of Mo into metallic phase, contributing to multiply hypo-hyper d-interaction, i.e. increase of electron density and mutual sharing of d-orbitals that provides electronic configuration more suitable for $\mathrm{H}^{+}$adherence and transference.

The final effect of improvement in the Co-based systems is not so remarkable as in case of Ni-based ones presented in the previous study [12]. But, taking into consideration that both studies are an entity, the final effect of improvement, starting with simple catalyst (pure Ni deposited on Vulcan XC-72) and ending with complex Co/anatase/MWCNTs catalyst is exellent, as expressed by $315 \mathrm{mV}$ decrease of overpotential.

\section{Acknowledgements}

This paper has been supported by and carried out within the EU Project "PROMETHEAS" PL ICA2-2001-10037 and Bilateral Project of Ministry of Education and Science of R. Macedonia with Ministry of Science of R. Bulgaria.

Special thank to the staff of the "Institute of Electrochemistry and Energy Systems", Bulgarian Academy of Science, Sofia for the fruitful collaboration and the hospitality in the Academy's laboratories during investigation.

Special gratitude to Prof. Milan Jakšić, University of Belgrade, for his bountiful and extensive help in the literature supply and valuable advices for both theoretical consideration and practical aspects of catalysts preparation.

\section{References}

[1] K. Lee, J. Zhang, H. Wang, D.P. Wilkinson, J. Appl. Electrochem. 36 (2002) 507.

[2] H.A. Gasteiger, S.S. Kocha, B. Sompalli, F.T. Wagner, Appl. Catal. B: Environ. 56 (2005) 9.

[3] D. Thompsett, in: W. Vielstichand, H.A. Gasteiger (Eds.), Handbook of Fuel Cells-Fundamentals, Technology and Applications, vol. 3, John Wiley \& Sons, New York, 2003, p. 467, Chapter 37.

[4] M.M. Jakšić, Č.M. Lačnjevac, B.N. Grgur, N.V. Krstajić, J. New Mater. Electrochem. Sys. 3 (2000) 169.

[5] M. Metikoš-Huković, A. Jukić, Electrochim. Acta 45 (2000) 4159.

[6] C. Fan, D.L. Piron, P. Paradis, Electrochim. Acta 39 (1994) 2715.

[7] I. Paseka, Electrochim. Acta 40 (1995) 1633.

[8] M.M. Jakšić, Electrochim. Acta 29 (1984) 1539.

[9] M.M. Jakšić, Int. J. Hydr. Energy 12 (1987) 727.

[10] M.M. Jakšić, J. New Mater. Electrochem. Sys. 3 (2000) 153.

[11] L. Brewer, Science 161 (1968) 115.

[12] P. Paunović, O. Popovski, A. Dimitrov, D. Slavkov, E. Lefterova, S. Hadži Jordanov, Electrochim. Acta 52 (2006) 1610.

[13] S.J. Tauster, S.C. Fung, R.L. Garten, J. Am. Chem. Soc 100 (1978) 170.

[14] S.G. Neophytides, S. Zaferiatos, G.D. Papakonstantnou, J.M. Jakšić, F.E. Paloukis, M.M. Jakšić, Int. J. Hydr. Energy 30 (2005) 131.

[15] W. Li, C. Liang, W. Zhou, j. Qiu, Z. Zhou, G. Sun, Q. Xin, J. Phys. Chem. B 107 (2003) 6292.

[16] P. Serp, M. Corrias, P. Kalck, Appl. Catal. A: Gen. 253 (2003) 337.

[17] S. Hadži Jorddanov, P. Paunović, O. Popovski, A. Dimitrov, D. Slavkov, Bull. Chem Technol. Macedonia 23 (2004) 101.

[18] B. Marsan, N. Fradette, G. Beaudoin, J. Electrochem. Soc. 139 (1992) 1889.

[19] L.M. Da Silva, L.A. De Faria, J.F.C. Boodts, Electrochim. Acta 47 (2001) 395.

[20] BG patent Appl. No. 38581.

[21] Y. Jin, G. Li, Yo. Zhang, Yu. Zhang, L. Zhang, J. Phys.: Condens. Matter. 13 (2001) L913.

[22] http://srdata.nist.gov/xps. djfsjd.

[23] M.A. Barakat, G. Hayes, S.I. Shah, J. Nanosci. Nanotechnol. 10 (2005) 1. 
[24] S.A. Chambers, S. Thevuthasan, R.F.C. Farrow, R.F. Marks, J.U. Thiele, L. Folks, M.G. Samant, A.J. Kellock, N. Ruziccki, D.L. Ederer, U. Diebold, Appl. Phys. Lett. 79 (2001) 3467.

[25] P. Paunović, O. Popovski, S. Hadži Jordanov, A. Dimitrov, D. Slavkov, J. Serb. Chem. Soc. 71 (2006) 149

[26] R. Paunović, O. Popovski, M. Tasev, R. Smilevski, S. Hadži Jordanov, Proceedings of the VIII seminar, Pardubice, Czech Republic, April 19-21, 2005, pp. 719-724.
[27] H. Kita, in: H. Bloom, F. Gootman (Eds.), Electrochemistry: The Past Thirty and the Next Thirty Years, Plenum Press, New York, 1977, p. 117.

[28] H. Ezaki, M. Morinaga, S. Watanabe, Electrochim. Acta 38 (1993) 557

[29] H. Ezaki, M. Morinaga, S. Watanabe, J. Saito, Electrochim. Acta 39 (1994) 1769

[30] S. Rausch, H. Wendt, J. Electrochem. Soc. 143 (1996) 2852. 